\title{
Information handling and adaptive expertise
}

\author{
Mark Hellen
}

(C) Springer Science + Business Media, LLC 2009

\begin{abstract}
This purpose of this paper is to argue the case for investigating the culture of information in primary schools. Recent technological change has altered the relationship between the individual and information, yet this change appears not to be reflected in the culture of schools, especially primary schools. To this end the area of the primary ICT curriculum which is categorised as "information handling" is examined, to investigate the current likely manifestation of this culture in schools. Using Hatano's concept of Adaptive Expertise as its theoretical perspective, the curriculum is analysed from the point of view of how well it is likely to prepare children for a life in which the ability to evaluate information will become a generically crucial skill needing to be applied in many varied and unforeseeable circumstances. Educational researchers have argued the case for change in the way we teach children to deal with information in schools; however this paper suggests that the existing culture of schools needs to be understood and opportunities for change identified if these skills are successfully to be introduced.
\end{abstract}

Keywords ICT · Internet - Information · Information Handling · Adaptive Expertise · Primary $\cdot$ Education $\cdot$ Curriculum $\cdot$ Culture

"Just think of the tragedy of teaching children not to doubt."

Clarence Darrow (1857-1938)

M. Hellen $(\bowtie)$

Goldsmiths College, University of London, London, UK

e-mail: m.hellen@gold.ac.uk 


\section{Information-the new relationship with the individual}

The internet has resulted in the most fundamental and far-reaching changes in the relationship between the individual and information. These changes have been caused by the fact that anyone can publish anything on the internet and new ways of organising, storing and retrieving information. $90 \%$ of children in the UK now have internet access outside school (Byron 2008), presenting them with direct access to a large, global and unfiltered source of information. In order to swim in this ocean of information of varying quality, reliability and relevance they will need to know how to filter information for themselves, how to become their own "editors-in-chief" and how to evaluate information for bias and accuracy. This has been acknowledged already (Bentley and Selzer 1999). What is not acknowledged however is the way schools are currently dealing with information and how the existing culture within schools, in particular primary schools, may be working against this need.

Shirky (2008) characterised the difference between the relationship individuals had with information before 1990 and that of today, noting that "filter then publish" has been replaced by "publish then filter". This represents the difference between the circumstances of today's primary school children and that of most adults when they were in school. It has more far-reaching consequences than may seem apparent to most at present. The filtering role, previously carried out by specialist gatekeepers such as teachers, editors, authors themselves and publishers now has to be carried out, in most instances, by individuals. This is of particular significance for children. Even with the best monitoring systems in place, whether adults insisting on being present when their children are accessing the internet, or having internet filtering programs in operation, none of these are foolproof and children have increasing opportunities for unsupervised use of the internet. Even if a child has very computerliterate and conscientious parents the likelihood is that not all their friends' parents will. The possibilities of accessing the internet from mobile devices continue to increase, as has already happened in Japan following the introduction of "i-mode" by NTT Docomo in the 1990s (Rheingold 2003). There, more than $90 \%$ of the population now own a mobile phone handset which has internet access ${ }^{1}$ (indeed SMS texting has never been widely used in Japan as all phones have had email capabilities since the mid 1990s). There, internet access from mobile devices overtook internet access from computers in $2006 .{ }^{2}$ Already in the UK it is not uncommon for mobile phones such as the iPhone and G1 to come with unlimited cost-free internet access. A similar situation to Japan is likely to be replicated in the UK as mobile phones with this feature become more common. It is expected that the Android open-source operating system for mobile phones will facilitate the sort of generative development of these devices which has been so rapid with regard to the internet and PCs (Zittrain 2008). Becta (2008) found that whilst 65\% of parents know how to deny children access to specific websites, $46 \%$ of children can get around these blocks. It also found that $13 \%$ of 11 -year-olds are never supervised while online, whilst $11 \%$ of 11 -year-olds say that their parents know nothing of their online activities.

\footnotetext{
$\overline{1}$ http://techcrunchies.com/mobile-internet-population-in-japan/ (undated)

2 http://www.engadgetmobile.com/2006/07/05/mobile-internet-access-outstrips-pc-access-in-japan/
} 
Therefore the option of protecting our children by cutting them off from the internet appears increasingly difficult, if not entirely unsustainable. If this is the case then children need to be educated to filter and evaluate what they encounter on the internet themselves. In order to assess its value children need to be able to decide whether a given piece of information they find on the internet is relevant to what they are looking for, whether it is designed to be informative, persuasive, or is potentially dangerous, who it is directed at and who is likely to have put it there Indeed if Baudrillard's (1998) argument, that the line between reality and unreality has become particularly blurred in contemporary life is accepted, it would suggest that the ability to critically evaluate information may also become an increasingly important skill outside cyberspace.

As such the need will be to protect children from harmful and undesirable material on the internet by enabling them to assess and evaluate information themselves. Two of the sub-skills of the ability to evaluate information are; understanding bias and understanding the ways information is organised and classified online.

\subsection{Bias}

One of the particular problems raised by the availability of unfiltered information on the internet is that a greater understanding of bias is likely to become more important when evaluating information. Prior to the spread of the internet this was probably much easier to do as it was normally unproblematic to establish the information's source, for example. Brown and Duguid (2000) argue that the metacognitive clues which are used to help assess the trustworthiness and bias of information, such as tone of voice and body language, which we rely on in interpersonal communication or the physical attributes of how and where something is published, do not always have direct equivalents on the internet. When the wider variety of sources available online and the lack of editorial screening of items published is taken into account, then there are likely to be problems encountered by children in their interactions on the internet when evaluating information.

Hirsh (2000) and Bilal (2000) both conclude that children fail to understand the need to check for bias and trustworthiness of sources of information they find on the internet and can be unselective regarding the information they find. Wineburg (1991) demonstrates that children's perceptions of bias are simplistic; that it appears for them to be a "black-and-white" issue with children perceiving that information is either biased or not biased. Recognising that to an extent all information is biased and that if children are to be able to safely use the internet as a source of information, then understanding that bias is a matter of different shades of grey may become an important educational issue.

\subsection{The organisation of information}

The Aristotelian way of organising information, in which everything had its place in a fixed order of things and which has hitherto dominated European perceptions of how information should be organised (Pellegrin 2005) is now beginning to be replaced by new, more fluid and less centrally-organised paradigms. Explaining the 
way the organisation of information has changed, Weinberger's (2007) three "orders of order" in particular identified the third order, where the information is stored digitally and accessed through a digitised database as the most significant change in the way information is stored and accessed. (p17).

It is significant because of its affordance of organising bits while Weinberger's first and second orders rely on physically organising atoms. Thus the digital nature of the third order removes the restrictions of physics still retained by first and second orders. Significantly, with regard to the culture currently pre-eminent in western societies he observes that;

"We have entire industries and institutions built on the fact that the paper order severely limits how things can be organised. Museums, educational curricula, newspapers, the travel industry and television schedules are all based on the assumption that in the second-order world, we need experts to go through information, ideas and knowledge and put them neatly away." (p7)

However the most significant affordance of third order classification systems is that their development has not merely been applied to centrally-determined taxonomies; the digitally-organised taxonomy has made way for what Tapscott and Williams (2006) term the "Folksonomy". Here, the information is classified by the users as they input the data rather than by experts centrally. As such it is argued that understanding how different people are likely to view the same thing differently will enable users to search more efficiently.

\subsection{1 st century needs}

As argued above, the demands on children in terms of the understanding they are likely to need to acquire; effective skills in Information Handling in the $21^{\text {st }}$ century, are qualitatively different from what was required of children in the past. The ability to apply this understanding to many different situations throughout their lives will be an important skill. Katayama (2008) demonstrates this as a result of the recent recession in Japan. Documenting how libraries needed to adapt their functions away from finding information for purely academic or recreational purposes, he documents how they are now assisting newly unemployed people find information to start their own enterprises or on subjects like vocational training courses and other work, as many adults do not possess these information handling and finding skills, noting that

"We learn a lot in school but it simply is not enough. Both knowledge and academic studies are constantly changing, if people rely only on what they have learnt at school, this will eventually be out of date." (p30 translated by the current author)

So what are we teaching children in primary schools with regard to Information Handling at the moment and how far will this promote the kind of abilities to enable them benefit from using the internet as a resource both now and in the future? The following section examines existing curricular arrangements for teaching Information Handling in primary schools in England from the perspective of its potential to provide children with the abilities to operate independently in the new information environment. 


\section{Information in primary schools}

'Information Handling' may be characterised as that element of the ICT curriculum which deals with;

- Finding information,

- Evaluating information from the point of view of relevance and bias

- Processing information through information processing programs such as databases

- Understanding how information is classified, categorised and organised.

This part of the current curriculum for ICT will be examined both from the perspective of this change in the relationship between the individual and information as well as from the perspective of Hatano's theory of 'adaptive expertise' (Hatano and Inagaki 1986), (Lin et al. 2007). Hatano's theory of Adaptive Expertise originated from the observation of experienced abacus users concluding that whilst all were procedurally competent and efficient, some were able to describe the principles upon which these skills were based and modify their practice according to the demands of new situations, or to learn from new situations rather than relying on previously learnt schemas which were not appropriate to the new situation.

Creating adaptive experts in ICT in general and more specifically Information Handling, is likely to be vital if children currently in school are to thrive and play a full part in society in the $21 \mathrm{st}$ century. The reason for this is that Information Handling is a rapidly developing area and one which is likely to continue to develop for the foreseeable future (Berners-Lee 2001).

Below, the existing situation with regard to information culture in primary schools will be examined from the evidence provided by current curricular arrangements and guidance for teachers and schools.

\section{Information handling in primary school}

\subsection{The current curriculum}

The QCA's, (The official UK body dealing with curriculum content and assessment) definition of ICT capability in schools comprises five elements; two of these five are related to Information Handling;

- understanding how information is structured in a database;

- skills in carrying out a search on the World Wide Web with sensitivity to meaning, accuracy of data and reliability of sources. ${ }^{3}$

The implication of this is that Information Handling is obviously considered an important element of ICT. The QCA Schemes of Work for schools in England for ICT (QCA 1997, updated 2003), as well as most other subjects were prepared in the mid 1990's initially as non-statutory guidance for teachers. Although theoretically

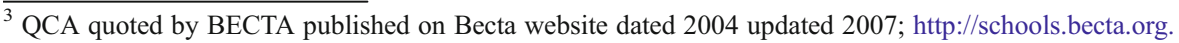
uk/index.php?section $=$ cu\&catcode $=$ Ss_cu_skl_02\&rid $=1701$
} 
not compulsory at the time of their publication, it was made clear by Ofsted, the schools inspectorate, that all schools would be expected to follow them closely unless they could show that their own schemes of work were superior. Ofsted's report on Information Technology in Primary Schools 2001/2002 (Ofsted 2002) clearly identifies "curriculum coverage" as a particularly important factor for primary ICT coordinators to monitor.

Few schools have the resources, or indeed the confidence to produce a scheme of work which they could be certain would be judged by Ofsted as equal or superior to that of the QCA. The likelihood is therefore that the QCA scheme of work for ICT has been adopted to a very large extent, along with the schemes of work for History, Geography and other subjects. Indeed it is likely that these schemes have become so widely embedded in primary schools in the UK as most commercial educational publishers and software suppliers have designed their materials specifically and exclusively to fit in with these schemes of work. ${ }^{4}$ A situation has been created where adherence to these schemes is relatively easy and non-adherence more costly in terms of resources and time. As a result, the QCA Scheme of Work for Primary ICT is likely to be very well established in primary schools.

An analysis of this scheme of work shows that it can be sorted into five basic strands. The proportion of the entire scheme taken up by these strands is shown in Fig. 1 below.

As is clear, the Information Handling strand is by far the largest, larger, for example, than both the sections relating to literacy and control technology combined, and comprising almost half of all ICT teaching within the 5-11 age range. The importance of skills relating to understanding how information exists, is stored, retrieved, manipulated, sorted and presented appear to reflect the priorities in the QCA's stated definition of ICT. In terms of its content the units which make up this strand are listed in Appendix 1.

\subsection{Analysis; how the QCA appears to envisage the teaching of information handling}

Insofar as how the ICT curriculum is realised in terms of what is taught in schools in England, four units central to the Information Handling strand are examined;

- Unit 1c "The information around us" intended to be taught in Year 1.

- Unit 3c "An introduction to databases" intended to be taught in Year 3.

- Unit 5c "Evaluating information, checking accuracy and questioning plausibility" intended to be taught in Year 5.

- Unit $6 \mathrm{~d}$ "Using the internet to search large databases and interpret information" intended to be taught in Year 6.

An analysis of this scheme of work with reference to what is considered current good practice in teaching and from the perspective of Adaptive Expertise however reveals serious weaknesses in its conception.

\footnotetext{
${ }^{4}$ For example, History, there is plenty of material for teaching about the Victorian period which ended in 1902, and for the Unit called "Britain since 1930". Yet there is little commercial material covering the period between 1902 and 1930, so children do not learn about the First World War, the Suffragettes and the Russian revolution
} 


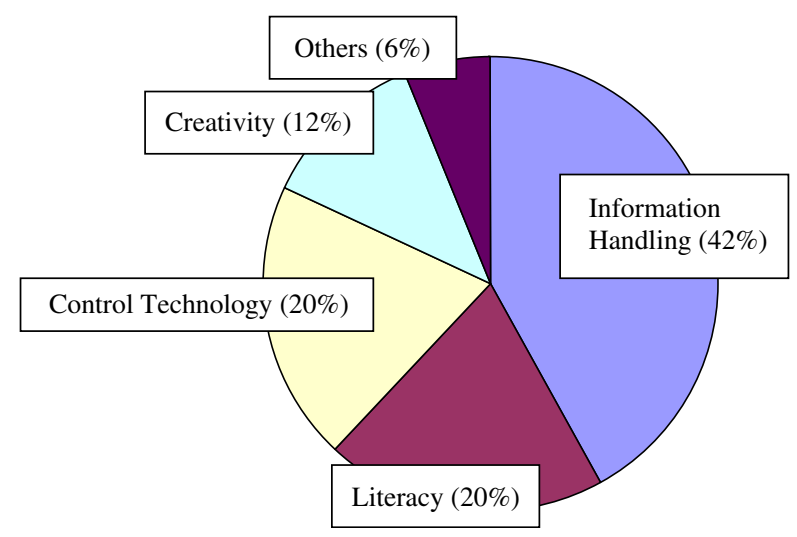

Fig. 1 Analysis of UK primary ICT scheme of work

\subsubsection{Unit 1C "the information around us"}

This unit contains the following instructions to the teachers;

"In this unit children learn that information exists in a variety of forms, including text, still and moving pictures, charts and sounds and that different media are used for different purposes."

The use of the passive here appears indicative of the thinking behind this unit; information is presented as given, not something to be questioned or understood in terms of why a particular piece of information is present, who is communicating what information to whom and for what purpose, all of which represent important aspects of children understanding and making sense of the world around them. Although the children are invited to discuss how different information is communicated they are not invited to question who is communicating and to whom it is being communicated and this is significant from a cultural perspective in that it suggests a passive relationship with information. There is a case to argue that this unit may have been more appropriately taught to older children where these issues might be explored in greater depth. Asking children to evaluate the information around them in terms of who is communicating it, how, to whom and for what purpose and how reliable it is would probably make the unit much more meaningful and generate much deeper and more effective learning. As it is, this unit appears merely to reinforce the notion that information is something handed down to children from above and of which they are passive consumers. This is particularly important from the point of view of how the culture of information within a primary school develops and will be discussed further in Section 4 below.

\subsubsection{Unit 3C, "introduction to databases"}

The inadequacies of the scheme with regard to information handling become even more evident when this unit is examined. The questions suggested for the teacher to ask pupils appear designed to encourage little more than the passive learning of how 
a database functions on an entirely practical level rather than to stimulate their interest and understanding of what a database is and what it can be used for;

"what information is on the fifth record card in the field 'legs'; which record contains the animal called 'woodlouse' in its name field; how many records are in the file; how many fields are in each record?" (QCA 1997)

Indeed this unit seems to be quite representative of many in the scheme as a whole in that it appears to be conceived as training as opposed to education. It gives the impression of having been created simply to train the children in the basic functions of a database, whilst avoiding explaining how or why they might use a database. The teacher, rather than the children, is asked to prepare a database and as such the opportunity for active, creative learning, whereby the children could create a database for a particular purpose, a potentially more effective activity, is lost. It seems that children are again treated as passive receptacles of information rather than being encouraged to think about the reasons for using a database. The 'integrated task' at the end of the unit invites children simply to create a class database rather than to create a database in order to investigate a particular research question.

Whilst it is not always easy to create a database, it is possible for children to do so if guided by teachers to help them frame research questions and work with them to devise and pilot information gathering activities an approach to teaching about databases supported by Spavold's (1989) research into database use in two primary schools.

As this unit exists at the moment this apparent focus on "training" rather than "education" led one primary school in west London including the following in its prospectus;

"Through ICT we prepare our children for the world of work." 5

Examining this and other aspects of the scheme, it would appear excusable that senior staff at this primary school had interpreted the Scheme of Work as vocational training as opposed to education. This is a prime example of children being given procedural competence but not being presented with a systemic understanding which would come from creating a database for a purpose and enable them to genuinely learn skills and understanding about database use and creation.

\subsubsection{Unit 5c "evaluating information, checking accuracy and questioning plausibility"}

This element of the curriculum appears to be more relevant to children's likely needs with regard to Information Handling. It explicitly wants children to check elements such as plausibility and accuracy yet it still appears to position children as passive recipients of teacher inputted information;

"Prepare a data file that measures a child's height from birth to the age of 12 and include one error. Show the data to the class and discuss how difficult it is to spot errors. Show how a line graph can help highlight errors."

Once again however, it is the teacher who is creating the database not the children and the plausibility checking is as a result of a mathematical error rather than, for

\footnotetext{
$\overline{5}$ Prospectus from a 5-11 primary school in the London Borough of Ealing 2003
} 
example, one of bias or wrongly categorised non-numeric information which might have more relevance to the children's own need to locate and interpret information on the internet. Although checking the plausibility of numerical data is important, it is probably also very likely that this will have been covered in Science or Maths. Evaluation of information from the point of view of accuracy in non-mathematical contexts is likely to be at least as important a skill. However it is the presentation of the concept of bias in this unit is of particular concern, it says;

"Discuss with the class how the unregulated nature of the Internet can lead to inaccurate or biased information."

This reinforces the perception of bias as the 'black and white' issue from children's point of view, identified by Wineburg (1991). In fact reinforcing the notion that there is 'inaccurate or biased' information on the internet subtly infers that there is also information which is totally accurate and without bias. Although it is appropriate to invite discussion about bias and about the systemic causes of this, it appears to be providing children, and indeed teachers themselves, with a false understanding of the nature of bias. Although there is some information on the internet which has been through the editorial process in the same way as most printed material, this information exists in an internet environment in which much other information available to children will have been put there by less benign sources. For example, even a site such as BBC News, which tries to maintain high standards of reliability, will have links to other sites which do not.

One of the ultimate consequences of teaching about bias, and how to evaluate information would be that children start to question some "old media" edited and published information which has been through the traditional editing/publication process. Children may start to understand that even information which has been through this process will still have a bias.

\subsubsection{Unit $6 d$ "using the internet to search large databases and interpret information"}

This unit does acknowledge the problem of teaching about finding information on the internet;

"It is important that teachers search the internet first for suitable sites. Without this, children can spend many hours in fruitless searching, without any reward."

however in spite of this acknowledgement of the difficulties that children face in searching the internet, the activities in the unit only attempt to deal with part of this problem. Out of 18 elements (listed in Appendix 2.) only 6 directly teach skills in information handling;

- to work with others to compare the most suitable sources and methods of searching

- to use a search engine to find information

- that information can be skimmed, sifted, selected and checked for bias

- to understand the importance of choosing key words to find information

- to use complex searches to locate information

- to look at information from different viewpoints and validate resources 
The onus appears once again to be on teachers providing children with information rather than the children finding it themselves. Yet the most notable aspect to this element is how a crucial issue like bias is relegated to just one part of only one out of 18 elements in the unit; "information can be skimmed, sifted, selected and checked for bias". Since some of these 18 elements include simple basic mechanical operations such as "accessing a website from a favourites list" this would appear to give teachers a sense of relative importance of these elements the balance of which is tilted substantially in favour of the mechanical skill of using the basic functions of a browser relative to the higher-order skill of examining information with regard to bias. The complex and relatively far more important intellectual function of determining bias is referred to as merely "checking for" as though it were a relatively uncomplicated issue such as checking spelling for example. The teaching activities related to the objective 'checking for bias' actually do not refer to bias at all and the teacher is instructed to restrict the children's navigating to 'pre-selected sites'. One of the most crucial elements in Hatano's criteria for a classroom in which children develop Adaptive Expertise is that of an element of randomness which exposes children to elements of the learning not directly under the control of the teacher. In terms of learning to search for and evaluate information, completely controlling what children are exposed to in the classroom is thus likely to be of limited effectiveness. It would appear that the children are being taught isolated mechanistic skills and are repeatedly not being given the systemic understanding they need to be able to adapt or transfer these skills to other contexts.

In relation to this, Mitra and Rana's (2001) research demonstrates that the basic functionality of most programs, such as web browsers, tend to be intuitive for most children to pick up. It is arguable therefore that teachers should be concentrating their teaching on areas such as bias and evaluation of information which are not necessarily intuitive for children and which present them with learning activities which are more likely to develop their cognitive abilities in these areas.

\subsection{The perspective of adaptive expertise}

The QCA Scheme appears to be increasingly out of date in relation to the needs of children and indeed the demands of parents. Livingstone and Bober (2005) found that $38 \%$ of pupils aged between 9 and 19 trust most of what they find on the internet, $49 \%$ trust some of it and only $10 \%$ are sceptical about a great deal of it. Only 33\% of 9 to 19-year-old regular internet users say that they have been told how to judge the reliability of online information. Yet the same study found that $75 \%$ of parents wanted more teaching and guidance for pupils in school on the use of the internet. This was second only to their desire for more restrictions on the availability of online pornography.

From the perspective of generating adaptive expertise in children the QCA scheme would appear to misunderstand the implications of the nature of the internet in the $21^{\text {st }}$ century. No systemic understanding of the different ways in which information can be stored is given, nor is any serious systemic understanding of the new relationship between the individual and information presented to children, and important issues such as bias and evaluation of information are not addressed in the kind of depth which their complexity would require. It could even be speculated that this scheme of work was deliberately designed, in 19th century fashion, simply to prepare children to go into relatively menial jobs in front of computer terminals. The 
questioning is often of a very low order (McComas and Abraham 2005) and tasks recommended are mechanical and appear to have little purpose. This is likely to result in much lower engagement with the subject matter on the part of the pupils and as such, result in less effective learning. Significantly it is also likely to foster a culture of passive acceptance with regard to information. With both Piagetian and Vygotskian perspectives on learning positioning children as active learners (Beard 1969) (Vygotsky 1978) they appear to have been ignored by the creators of this scheme. Hatano's ideas would suggest that children's active inquisitiveness needs to be developed in the direction of systemic understanding and creative, adaptive use.

The implication of this is that the existing ICT curriculum may be failing to prepare children for life in the $21^{\text {st }}$ century. Yet it goes further than this; given the change in the relationship between the individual and information, the QCA Scheme seems to be working against the interests of the children by treating them as passive learners. If we consider how important Vygotsky considers cultural influences on learning to be then we appear to be generating a culture within schools which, from an early age, discourages the kind of active, creative, critical thought which children are going to need in order to make sense of and thrive in the virtual world around them. If, initially, we teach children simply that information exists in different forms as though all information is accurate and valid, then the idea that information was put there by someone for a reason and that information is not something which needs to be at least questioned, then it is likely to be more difficult to educate children to evaluate and filter information they see on the internet at a later stage.

The highly controlled nature of many of the units, where material is pre-selected by teachers or created in advance for children by teachers appears to be part of the problem. Hatano (Hatano and Inagaki 1986) noted that it was the opportunity for children to engage in experimentation in situations where random elements had not been removed which seemed to result in the development of adaptive expertise.

"A culture where understanding the system is the goal, encourages individuals in it to engage in active experimentation. That is, they are invited to try new versions of the procedural skill, even at the cost of efficiency" (p270).

Yet the QCA scheme appears to offer little more than simple procedural skills, presenting children with training rather than education. Hatano's differentiation between understanding mere skills and acquiring systemic knowledge and understanding is especially significant in the case of ICT generally and Information Handling in particular. Comparing what he describes as a "Performance-oriented classroom" and an "Understanding-oriented classroom", the former is characterised as resulting in procedural fluency only, while the latter engenders procedural fluency complimented by explicit conceptual understanding. In terms of Information Handling, adaptive expertise will only come from a development of skills in evaluating information, a clear conceptualisation of bias and a secure understanding of how information is organised, retrieved, as well as subjectively perceived, classified and categorised.

\subsection{The response of the rose review}

The Rose Review (DCSF 2009; 34) and the BECTA contribution to it (BECTA 2009: 13), both recognise the need for children to be able to evaluate information; 
however the need to address the existing culture of schools in order to facilitate this appears not to have been addressed. Indeed, one of the criticisms made above, that the curriculum focuses too much on detail remains valid, particularly since Rose concentrates significantly on what it perceives as the requirement to assess children comprehensively. It is this assessment-driven approach which is potentially problematic in terms of developing Adaptive Expertise in an area such as Information Handling. This is not a simple set of skills, the learning of which can easily be assessed; they are skills children may take some time to develop. As such the over-reliance on assessment may result in teachers focussing on elements which can more easily assessed, which are likely to be those more mechanical and lowerorder skills, such as the basic operation of programs, which, from the evidence of Mitra and Rana (2001) children appear to have few problems in acquiring.

\section{Conclusion}

Up to now there has appeared to be little need to encourage children to evaluate information, particularly in the school context. Information did not generally need to be doubted by those receiving it except in relatively specific situations. It was always filtered, if not by publishers, editors, producers, directors and broadcasters then by teachers. As Weinberger (2007) suggested, the culture within schools, like that of other institutions, is still one which represents the situation prior to the changes in the availability of information on the internet. The culture of schools in which the teacher still appears to be regarded as the gatekeeper of knowledge and the way schools and the curriculum are organised still reflects this.

If children in primary schools, particularly upper primary, are not able critically to evaluate information, then it is probable that this is because we have a culture within schools, or possibly within society generally, which encourages uncritical acceptance of information. A culture in school which treats information as something to be questioned and evaluated needs to be encouraged in all aspects and curriculum areas; it would appear that at present, young children are being encouraged to think differently from the way they will need to by the time they reach the later stages of primary schools and go to secondary school.

It is doubtful therefore, whether the existing approach to the curriculum and the current culture relating to information are capable of providing children with the skills to develop adaptive expertise in relation to Information Handling. Indeed, if the QCA schemes are anything to go by, the antithesis of the kind of information culture needed now appears prevalent in both primary and secondary schools. The culture, still one of "teaching to test" (EPPI 2002) brought about by a test and examination-centred school system could be argued to further promote an uncritical acceptance culture in relation to information. It may be that the assessment culture currently predominant within English schools is one which works against the development of more complex higher-order skills such as evaluating information and determining bias.

Many have argued that schools need to change as a result of ICT and the opportunities for creative, individualised and independent learning it is bringing. Whilst some change may in the end not be possible since schools are still 
constrained by a number of social, economic and physical functions which are unlikely to be altered substantially by new technology, in conclusion this paper recommends (below) possible ways forward for how this change might proceed by altering the current culture of passive acceptance of information and introducing more opportunities for children to develop adaptive expertise in Information Handling.

As long ago as 1999 Bentley and Seltzer, in a report published by the think-tank Demos and sponsored by the QCA, observed that;

"The central shift is from a model of learning and consumption which rested on established channels of information-textbooks, teachers, company research departments, newspapers - to one where there is a larger and more chaotic range of data accessed through more varied and fluid channels." (p 21).

Despite its sponsorship of this kind of forward thinking, it is clear that the QCA has remained conservative about the way it sees how the curriculum relating to information handling is taught in schools. Indeed whilst Bentley and Seltzer's report may have been accepted in terms of the new paradigm of information organisation, the implications of this in terms of its impact, in more concrete terms, on the curriculum and the culture within schools appears not to have been addressed.

MORI (2008) found that, of all activities children did in the classroom "Copying from the board or from a book" and "Listening to the teacher talking for a long time." were the two most common. This strongly suggests that the culture within schools remains one in which children have little opportunity to question what they are told, nor engage in any critical evaluation of information. Establishing the current state of the information culture in schools would therefore be an important element for further research, since this is likely to indicate the extent to which schools need to change in order to provide for the needs of the children in the context of the $21^{\text {st }}$ century.

\subsection{Recommendations}

The Independent Review of the Primary Curriculum (DCSF 2009) has suggested that the ICT curriculum be reorganised and that Becta and the QCA should consider moving some elements of the ICT curriculum now in secondary schools to the primary school curriculum. The Review clearly supports the need to cultivate children's enquiring minds and stresses the need for children to be able to;

"think for themselves and process information, reason, question and evaluate"

This represents an opportunity for a systematic review of Information Handling as an area of particular generic importance for all areas of the curriculum and to establish a greater coherence and prioritisation for this increasingly crucial area of children's learning. However the culture of information in schools may take longer to change than expected. In addition to recommending further research into the information culture of schools, suggested above, the main recommendation which needs to be made is that further study is undertaken to discover at what stage children are capable of developing these kinds of critical, evaluative and adaptive 
skills. Spavold's (1989) research, referred to in Section 3.2.2 above would suggest that children are capable of more than currently realised.

The need is not merely for change in the ICT curriculum however, the way all subjects are approached and indeed the entire culture prevalent in schools needs to change, an undertaking which, given the evidence presented above, is unlikely to be straightforward. The first step in achieving this would probably be establishing an honest and direct discussion with teachers about these issues, if we are to expect them to teach these skills to children, then the top-down approach where schemes of work, teaching methods, school management structures and assessment arrangements are all handed down from on high as has been the case in the last 25 years will be inappropriate. Indeed even the language of Ofsted, presenting their inspections as established, incontrovertible fact, rather than professional opinions and judgements may need to change.

If this area of education is to change, this will need to be done in a different way from all educational changes made since 1986. Because of the nature of the issues teachers need to be given the opportunity to debate these issues, if meaningful change in this area is to be effective. Children in primary schools should not be disadvantaged in terms of their expectations and perceptions of how their lives will be when they are older. Educating children to become critical, independent lifelong learners who can adapt what they learn to as yet unforeseeable situations is the goal. Training children for a relatively passive existence may have been regarded positively in the past but it is no longer a viable option for the future.

\section{Appendix 1. Units making up the Information handling element of the QCA scheme of work for ICT in key stages I and 2}

$\begin{array}{ll}\text { Year group } & \text { Title of Unit } \\ \text { Year } 1 \text { (5-6 years) } & \text { The information around us } \\ \text { Year } 1 \text { (5-6 years) } & \text { Labelling and classifying } \\ \text { Year } 1 \text { (5-6 years) } & \text { Representing information graphically: pictograms } \\ \text { Year } 2 \text { (6-7 years) } & \text { Finding information } \\ \text { Year } 2 \text { (6-7 years) } & \text { Questions and answers } \\ \text { Year } 3 \text { (7-8 years) } & \text { Introduction to databases } \\ \text { Year } 4 \text { (8-9 years) } & \text { Branching databases } \\ \text { Year } 4 \text { (8-9 years) } & \text { Collecting and presenting information; questionnaires and pie charts } \\ \text { Year } 5 \text { (9-10 years) } & \text { Analysing data and asking questions; using complex searches } \\ \text { Year } 5 \text { (9-10 years) } & \text { Evaluating information, checking accuracy and questioning plausibility } \\ \text { Year } 5 \text { (9-10 years) } & \text { Monitoring environmental conditions and changes } \\ \text { Year } 5 \text { (9-10 years) } & \text { Introduction to spreadsheets } \\ \text { Year } 6 \text { (10-11 years) } & \text { Spreadsheet modelling } \\ \text { Year } 6 \text { (10-11 years) } & \text { Using the internet to search large databases and to interpret information }\end{array}$




\section{Appendix 2. Breakdown of unit 6d in the QCA scheme of work for primary ICT}

- to print a page from the internet

- that it is important to interpret information and to understand it

- to work with others to compare the most suitable sources and methods of searching

- to type in a URL to locate a web page

- to save and use pictures and text and import into a document for a presentation

- that copyright and acknowledgment of sources is understood

- to access an internet site using a favourites list

- to use a search engine to find information

- to search the internet using 'and'

- to use hyperlinks to trail an idea

- that information can be skimmed, sifted, selected and checked for bias

- to understand the importance of choosing key words to find information

- to use complex searches to locate information

- to work with others to interpret information

- to look at information from different viewpoints and validate resources

- to use word processing or DTP to organise and present information suitable to an audience

- to use e-mail as a means of receiving feedback on ideas

- that the printed information is understood (QCA Scheme of Work for ICT Unit 6d)

\section{References}

Baudrillard, J. (1998). Simulacra and simulations. In Poster, M (Ed) Jean Baudrillard, Selected Writings. Stanford University Press pp 166-184.

Beard, R. (1969). An outline of piaget's developmental psychology. London: Routledge \& Kegan Paul. BECTA (2009) BECTA'S Contribution to the Rose Review. BECTA. Coventry.

Berners-Lee, T. (2001). The Semantic Web. Scientific American. May 2001.

Bentley, T., \& Selzer, K. (1999). The creative age: knowledge and skills for the new economy. London: Demos.

Bilal, D. (2000). Children's use of Yahoologans! Web search engine: 1. Cognitive, physical and affective behaviors on fact-based search tasks. Journal of the American Society for Information Science, 51 (Part 7), 646-665.

Brown, J. S., \& Duguid, P. (2000). The social life of information. Cambridge Mass: Harvard Business School Press.

Byron, T. (2008). Safer children in a digital world. DCSF Publications. London http://www.desf.gov.uk/ byronreview/pdfs/Final\%20Report\%20Bookmarked.pdf. Accessed 10 January 2009.

DCSF (2009) Independent review of the primary curriculum. London: DCSF.

EPPI (2002). A Systematic Review of the Impact of Summative Assessment and Tests on Students' Motivation for Learning. http://eppi.ioe.ac.uk/cms/Default.aspx?tabid=108. Accessed 10 January 2009.

Hatano, G., \& Inagaki, K. (1986). Two courses of expertise. In H. Stevenson \& K. Hakuta (Eds.), Child development and education in Japan. New York: Freeman.

Hirsh, S. (2000). Children's relevance criteria and information seeking on electronic resources. Journal of the American Society for Information Science., 50(14), 1265-1283.

Katayama, Y. (2008). "Chiteki rikkoku to shite no toshokan to sono kanousei". Language, 37(9), 28-33. Translation; "Libraries support lifelong learning". 
Lin, X., Schwartz, D., \& Bransford, J. (2007). Intercultural adaptive expertise; explicit and implicit lessons from Dr Hatano. Human Development, 50(1).

Livingstone, S., \& Bober, M. (2005). Children go online: final report of key project findings. LSE Research Online. London http://eprints.1se.ac.uk/399/1/UKCGO_Final_report.pdf Accessed 10 January 2009.

McComas, W., \& Abraham, L. (2005). Asking more effective questions. http://www.usc.edu/programs/cet/ private/pdfs/usc/Asking_Better_Questions.pdf. Accessed 10 January 2009.

Mitra, S., \& Rana, V. (2001). Children and the internet: experiments with minimally invasive education in India. British Journal of Educational Technology, 32(2), 221-232.

MORI (2008) State of the nation survey 2008. Campaign for Learning: London.

Ofsted. (2002). Information and Communication Technology in Primary Schools. http://www.archive2. official-documents.co.uk/document/deps/doh/hc286/prim-ict.htm Accessed 10 January 2009.

Pellegrin, P. (2005). The aristotelian way. In M.-L. Gill \& P. Pellegrin (Eds.), (2006) A companion to ancient philosophy (pp. 235-244). Hoboken NJ: WileyBlackwell.

Qualifications and Curriculum Authority. (1997). ICT at Key Stages 1 and 2. http://www.standards.dfes. gov.uk/schemes2/it/ accessed 10 January 2009.

Rheingold, H. (2003).. Smart mobs: the next social revolution. Perseus.

Shirky, C. (2008). Here comes everybody: the power of organizing without organizations. New York: Allen Lane.

Spavold, J. (1989). Children and databases:an analysis of data entry and query formulation. Journal of Computer Assisted Learning, 5, 145-160.

Tapscott, D., \& Williams, A. (2006). Wikinomics: how mass collaboration changes everything. New York: Portfolio.

Vygotsky, L. S. (1978). Mind in society; the development of higher psychological processes. Cambridge, Mass: Harvard University Press.

Weinberger, D. (2007). Everything is miscellaneous. New York: Henry Holt.

Wineburg, S. (1991). Historical problem solving: a study of the cognitive processes used in the evaluation of documentary and pictorial evidence. Journal of Educational Psychology, 83(1), 394-412.

Zittrain, J. (2008). The future of the internet and how to stop it. New York: Allen Lane. 